\title{
Can gold hedge against inflation in the UAE? A nonlinear ARDL analysis in the presence of structural breaks
}

\author{
Nassar S. Al-Nassar \\ Department of Economics and Finance, College of Business and Economics, \\ Qassim University, Buraydah, Saudi Arabia
}

\begin{abstract}
Purpose - The purpose of this study is to explore the role of gold as a hedge against inflation in the case of the United Arab Emirates.

Design/methodology/approach - The study utilizes monthly data on the local sharia-compliant spot gold contract traded on the Dubai Gold and Commodity Exchange (DGCX) and the corresponding consumer price index series over the period December 2015 to January 2021. The econometric approach employed by the study involves a unit root testing procedure that allows the timing of significant breaks to be estimated. A cointegration analysis is then conducted using a nonlinear autoregressive distributed lag (NARDL) model, taking into consideration the presence of structural breaks in addition to short- and long-run asymmetries.

Findings - The results reveal that consumer and gold prices are cointegrated, which implies that investing in gold can hedge against inflation in the long run. No sufficient evidence, nonetheless, is found in support of the ability of gold to serve as a hedge against inflation in the short run.

Originality/value - The findings have several important policy implications for policymakers and investors that are further discussed in the study.
\end{abstract}

Keywords Gold, Inflation, Hedging, Nonlinear autoregressive distributed lag (NARDL) model, United Arab Emirates (UAE)

Paper type Research paper

\section{Introduction}

For thousands of years, gold has served as a major medium of exchange and store of value. This role continued until the demise of the Bretton Woods system in 1971. Since then, gold has been traded freely on the world's markets [1]. The price of gold increased approximately 54 -fold in nominal terms from US\$35 per ounce in 1970 to US $\$ 1887.60$ per ounce by the end of 2020. This upward trend captured the interest of investors. Erb et al. (2020) show that the real price of gold increased with the gold holdings of the largest two gold exchange-traded funds (ETFs), which constitute the majority of ETF investor demand $[2,3]$.

Gold as an asset class is traditionally viewed as a good hedge against inflation - or a "golden constant," in the terminology of Jastram (1978) [4]. Gold enjoys this status because it has distinctive features that set it apart from most commodities (see, Worthington and Pahlavani, 2007, p. 259). Arnold and Auer (2015, p. 198) elegantly delineate these features as follows: "First, gold's intrinsic value neither depends on prospective cash flows nor carries a default risk. Second, gold is universally acceptable and scarce. Third, the relative inelasticity

(C) Nassar S. Al-Nassar. Published in PSU Research Review. Published by Emerald Publishing Limited. This article is published under the Creative Commons Attribution (CC BY 4.0) licence. Anyone may reproduce, distribute, translate and create derivative works of this article (for both commercial and noncommercial purposes), subject to full attribution to the original publication and authors. The full terms of this licence may be seen at http://creativecommons.org/licences/by/4.0/legalcode.

The author received no financial support for the research, authorship, and/or publication of this article.

Received 4 August 2021 Revised 20 October 2021 Accepted 21 November 2021 
of the gold supply and the observed counter-cyclical demand qualify gold as a store of value. Finally, and probably most importantly, a protection property is commonly attributed to gold by many investors, individuals, and the media."

The role of gold as a hedge against inflation has received considerable attention in the literature. This notion of gold as an inflation hedge is rooted in the Fisher (1930) hypothesis, which predicts a positive correlation between asset returns and inflation rates. However, the empirical results have not produced an agreement about the nature of the gold-inflation nexus. The evidence obtained by empirical studies can be divided into three categories, in the spirit of Arnold and Auer (2015): first, studies that provide strong support for the role of gold as a hedge against inflation, including, among others, Ghosh et al. (2004), Worthington and Pahlavani (2007), Le Long et al. (2013) and Shahbaz et al. (2014); second, studies with mixed results across countries, sample periods or econometric techniques, including, for example, Chua and Woodward (1982), Taylor (1998), Beckmann and Czudaj (2013) and Shahzad et al. (2019); and finally, studies that refute the inflation-hedging ability of gold, such as Brown and Howe (1987) and Mahdavi and Zhou (1997).

Of the extant studies in the literature, few have examined the gold-inflation nexus in emerging markets. Among them are Adekoya et al. (2021), who investigate the relationship between inflation and the prices of several precious metals, including gold, in six major African mining countries (namely, Congo, Ghana, Morocco, Namibia, South Africa and Tanzania), whereas the studies of Le Long et al. (2013) and Shahbaz et al. (2014) are conducted in single-country settings, focusing on Vietnam and Pakistan, respectively. While the findings obtained by Le Long et al. (2013) and Shahbaz et al. (2014) support the effectiveness of gold as an inflation hedge, Adekoya et al. (2021) find that silver, not gold, is the best hedging tool against inflation risk in the majority of countries under investigation.

These variations in findings across studies perhaps appear due to the cultural aspects of gold and related customs controls and regulations on the gold trade in certain countries (Hoang et al., 2016). Another reason could be the occurrence of different economic events and conditions during certain time periods (for example see, Shahzad et al., 2019; Taylor, 1998; Worthington and Pahlavani, 2007). Given the heterogeneity of the results of previous studies, it would be beneficial to consider other countries to examine the gold-inflation nexus in a new context. Indeed, several Middle Eastern countries are among the world leaders in terms of gold jewelry consumption and gold retail investment. The United Arab Emirates (UAE), in particular, stands out as a good candidate country for empirical analysis for the following reasons:

(1) The UAE is fourth in the world in terms of gold jewelry consumption, preceded only by India, China, and the US, while occupying first place among Middle East and North Africa (MENA) countries in the amount of gold retail investment (Refinitiv, 2020).

(2) The central bank of the UAE increased its gold reserves more than sevenfold from 7.5 tonnes in 2015 to 57.60 tonnes by the end of 2020 (World Gold Council, 2021b).

(3) The Dubai Gold and Commodity Exchange (DGCX) is the first and only commodity exchange in the MENA region. Furthermore, the DGCX introduced the first-ever sharia-compliant spot gold contract, which can be used as a benchmark by shariacompliant commodity ETFs across majority-Muslim countries.

(4) The importance of the UAE stems from its status as the region's current headquarters hub. Therefore, not only UAE nationals and local businesses but also expats and multinationals operating in the UAE are affected by inflation in the country.

With the above in mind, we intend to fill the gap in the literature by examining the goldinflation nexus in the case of the UAE. Our humble effort is an attempt to contribute to the literature in two main ways. First, this is an inaugural study that investigates the relationship 
between gold prices and inflation in the case of the UAE. We analyze local gold prices (DGCX sharia-compliant spot gold) instead of relying on London gold prices converted into local currencies, which is what most prior studies do. Second, on the methodological front, we employ a unit root test allowing for structural breaks to ameliorate the potential bias in standard unit root tests in series containing a structural change. Moreover, we use the nonlinear autoregressive distributed lag (NARDL) approach of Shin et al. (2014) to analyze the relationship between gold and consumer prices. This approach possesses several desirable features: (1) The bounds test of cointegration can be used even if both series are not integrated of order one, provided that none of the series are integrated beyond order one. (2) The NARDL approach can account for short- and long-run asymmetries simultaneously in the presence of structural breaks. Therefore, the results that emerge from this approach can be used to judge the hedging effectiveness of gold against inflation in both the short and the long run.

The results obtained show that the relationship between gold and consumer prices is asymmetric in the long run and provide strong evidence that gold and consumer prices are cointegrated. In the short run, however, the comovement of gold and consumer prices is much weaker, which implies that gold can serve a hedge against inflation in the long run only. Plausible explanations for these findings are discussed along with their practical implications.

\section{Literature review}

Motivated by the collapse of the Bretton Woods system and the rising awareness of inflation risks in the 1970s, several studies investigated the effectiveness of gold as a hedge against inflation. Early research endeavors include Kolluri (1981), Chua and Woodward (1982), Brown and Howe (1987), Jaffe (1989), Mahdavi and Zhou (1997), and Taylor (1998). Using the Fisher regression (regressing gold returns on the inflation rate), Chua and Woodward (1982), based on a sample of six industrialized economies (Canada, Germany, Japan, Switzerland, the UK and the US) for the period 1975 to 1980, find that gold acts an inflation hedge only in the US. Investigating a slightly longer sample period spanning 1971-1987 but limited to the US, Jaffe (1989) finds no support for the hedging ability of gold, as the Fisher regression coefficient is nonsignificant with a poor fit. Brown and Howe (1987) show that a hedged cash position (constructed by buying gold in the spot market while shorting a future on gold) does not provide a hedge against inflation.

Mahdavi and Zhou (1997) and Taylor (1998) employ cointegration techniques to investigate the long-run relation between commodity prices, including gold, and the consumer price index (CPI) in the US. Mahdavi and Zhou (1997) use a sample starting in 1970 that coincides with the beginning of the flexible pricing of gold and a longer sample pertaining to other variables and starting in 1958. Both samples end in 1994. They control for economic and financial conditions by including real gross domestic product and short-term interest rates in the Johansen (1988) multiple cointegration framework. The results show that gold and CPI are not cointegrated, which indicates that gold is not an inflation hedge even in the long run.

Taylor (1998) analyzes a longer sample spanning some 80 years from 1914 to 1996. Using several estimation techniques, he examines the short- and long-run relation between gold and other precious metals and inflation. The results that emerge from this study are that the shortrun inflation relation is time-varying, holding in particular during the prewar period and around the second OPEC oil crisis in 1979. In contrast, the results obtained from cointegration analysis indicate that gold can be used as a hedge against inflation, as the price of gold and the CPI are found to be cointegrated, albeit not with a one-to-one correspondence.

To reconcile the contradictory results about the hedging ability of gold in the short and long run, Ghosh et al. (2004) derive a model for gold price determinants and use it as a basis for 
their empirical analysis. Using a US-based sample spanning the period 1976-1999, they employ the Johansen (1988) multiple cointegration framework. Their results provide support for the presence of a long-run relation between gold and CPI; thus, gold can be regarded as a hedge against inflation in the long run.

More recent studies argue that time series dynamics such as structural breaks, nonlinearity (asymmetry), and the time-varying nature of the relation between gold prices and goods prices must be taken into consideration (Bampinas and Panagiotidis, 2015; Batten et al., 2014; Beckmann and Czudaj, 2013; Hoang et al., 2016; Lucey et al., 2017; Wang et al., 2011; Worthington and Pahlavani, 2007). Therefore, they employ state-of-the-art econometric techniques to model these dynamics.

Worthington and Pahlavani (2007) highlight the importance of accounting for structural breaks in cointegration analysis. The sample used in their analysis covers only the US, spanning the period from 1945 to 2006. To determine structural breaks endogenously, they employ a (1992) unit root test. Using the break points determined by the method of Zivot and Andrews (1992), they test for the presence of a cointegrating relation between gold and inflation by the means of a Saikkonen and Lütkepohl (2000a, b, c) cointegration test that allows for structural breaks. Their results show that the estimated break points correspond to the start of free trading of gold and the rising inflation in the 1970s and that gold in the postwar period is cointegrated with inflation, suggesting that gold is an effective hedge against inflation.

To account for potential nonlinearity in the gold-inflation nexus, Wang et al. (2011) employ the threshold cointegration approach of Enders and Siklos (2001) along with the traditional Engle and Granger (1987) cointegration test. They investigate the long- and shortrun hedging effectiveness of gold against inflation in the US and Japan during the period 1971 to 2010. The Engle and Granger (1987) test finds evidence for cointegration between gold and CPI in the US only. While the Enders and Siklos (2001) threshold cointegration approach finds strong evidence for nonlinearity (asymmetry) in Japan, no traces of nonlinearity are found for the US. Their findings indicate based on the cointegration coefficient that gold is a perfect hedge against inflation in the US but is only partially effective in Japan. The authors extract an important insight from the nonlinear threshold cointegration analysis. They show that the hedging effectiveness of gold against inflation rests on whether the adjustment momentum regime between gold and consumer prices is high or low. On the one hand, gold cannot hedge against inflation in either the US or Japan during low-momentum regimes. On the other hand, during high-momentum regimes, gold effectively serves as a hedge against inflation in the US, while price rigidity in Japan precludes gold from fully hedging inflation risk in the short run.

Beckmann and Czudaj (2013) extend previous studies in two ways. First, they broaden the sample of countries to include the US, the UK, the Euro area and Japan over the period 19702011. Second, to relax the assumption required when the Enders and Siklos (2001) approach is used, namely, that the regime variable is endogenous, they employ the Johansen $(1988,1991)$ cointegration test and a Markov-switching vector error correction model (MS-VECM), where the unobservable state follows an exogenous stochastic process. The results obtained from the Johansen test show evidence of cointegration between gold and CPI across all countries, although the inflation hedging ability is better for the USA and the UK than for Japan and the Euro area. Furthermore, the change in the CPI is regime-dependent in that one regime roughly captures periods of turmoil, while the other approximately coincides with "normal" times, implying that the hedging performance of gold relies heavily on the time horizon.

In a similar vein, Bampinas and Panagiotidis (2015) use a long sample of annual data for the US and the UK over the period 1791-2010 to explore the long-run dynamics of the goldinflation nexus. Using several CPI metrics, they employ the Johansen (1988, 1991) cointegration test and a time-varying vector error correction model (TV-VECM). Their 
results can be summarized as follows: First, the real price of gold is found to be stationary when unit root tests allowing for structural breaks are employed. Second, cointegration results are sensitive to the CPI metrics used for both the US and the UK. Third, the (long-run) cointegration coefficient is found, on average, to exceed unity, which implies that the gold price more than fully hedges against inflation in both countries, although the long-run coefficient is higher in the US. Fourth, the long-run hedging performance of gold against expected inflation became more stable in the last decade.

Batten et al. (2014), based on US data for the period 1985 to 2012, find no evidence of cointegration between gold and consumer prices using three econometric techniques (Johansen, 1988, 1991), ARDL and Saikkonen and Lutkepohl tests). To investigate the timevarying relation between gold and consumer prices, the authors employ a Kalman filter approach. Furthermore, time-varying gold's CPI beta derived from the Kalman filter approach is also utilized to determine whether the relation can be explained and/or forecast by various macroeconomic state variables. They find that a contemporaneous, statistically significant, negative relation exists between changes in gold's inflation beta and the value of the US dollar. In addition, the Granger causality test indicates that short- and long-term interest rate changes forecast changes in gold's beta.

Using an unbalanced sample of local gold prices in China, India, Japan, France, the UK and the US, Hoang et al. (2016) investigate the hedging ability of gold by means of a NARDL model. The rationale for the selection of this approach stems from its ability to account for short- and long-run asymmetries simultaneously, in contrast to the techniques used by Wang et al. (2011) and Beckmann and Czudaj (2013), with the former accounting only for long-run asymmetries and the latter only for short-run asymmetries. Their results for the long run indicate that gold fails to provide a hedge against inflation across all countries. The short-run results are indicative of a slightly more promising performance of gold as a hedge against inflation - in half of the cases (i.e. the UK, the US and India), gold hedges against inflation. The authors attribute the mixed results to differences in traditional (cultural) meanings of gold and pertinent customs controls and regulations on gold trading.

Lucey et al. (2017) corroborate the findings of prior studies about the time-varying nature of the cointegrating relation between gold prices and consumer and producer price indices for three major economies: Japan, the UK and the US over the period 1974-2014. The novelty of this study derives from its examination of the relation between gold and the money supply. The results obtained show that the price of gold keeps up with the increase in the money supply over nearly the entire sample period, but only in the US and the UK. Lucey et al. (2017) highlight the importance of the money supply in the gold-inflation nexus and cast doubt on the appropriateness of the use of the CPI index as an indicator of this relationship.

Using the same set of countries studied by Hoang et al. (2016), i.e. China, India, Japan, France, the UK and the US, Shahzad et al. (2019) employ quantile-on-quantile (QQ) and causality-in-quantile approaches. Their empirical findings are twofold. First, based on the QQ method, the authors do not find a consistently positive relationship between gold and inflation across all quantiles for all countries, suggesting that the inflation-hedging ability of gold differs under different economic conditions in certain countries - the gold-inflation nexus varies across the six countries, and the slope coefficient is altered across the different quantiles of CPI growth and gold growth within each economy. Second, the results based on the nonparametric causality-in-quantile method show evidence of Granger causality in mean from the CPI to gold in the middle quantiles for most countries except France, where evidence of a causal flow in both the mean and the variance across all quantiles is found. The thrust of their results is that gold may serve as a hedge against inflation only in the mid-quantile ranges or under normal economic conditions.

The focus of the literature has been, to a large extent, on the gold-inflation nexus in the US and a few major industrialized economies. However, the findings of these studies are far from 
uniform across these countries, let alone developing countries, which has motivated several authors to explore the aforementioned relation in a multicountry setting. Sharma (2016) uses an unbalanced data set from 54 countries to determine whether consumer prices predict gold price returns. The results indicate that while CPI has limited in-sample forecasting ability for gold price returns, out-of-sample tests show a relatively stronger CPI forecasting ability.

Salisu et al. (2019) examine the hedging ability of gold (and palladium) in 32 Organisation for Economic Co-operation and Development (OECD) countries. They deploy several econometric techniques, starting with a simple time series Fisher regression as their baseline model (and test its forecasting performance) and then extend the model by incorporating asymmetries in inflation rates and controlling for structural breaks. They segment the sample into pre- and post-GFC periods and run a panel ARDL. The results on gold's hedging potential vary across countries, models and subsamples. However, the authors suggest that gold generally provides a hedge against inflation in OECD countries, despite the varying results across individual countries.

Adekoya et al. (2021) consider gold, among other precious metals, as a candidate for hedging inflation in six major African mining countries (namely, Congo, Ghana, Morocco, Namibia, South Africa and Tanzania) using an unbalanced sample over the period 1995 to 2019. They compare the adequacy of three models: the first is the baseline model (a simple time series Fisher regression), the second is a Fisher regression that controls for asymmetries in inflation rates and the third is a regime-switching regression. In addition, to control for the macroeconomic determinants of the price of precious metals, they augment the baseline model with the exchange rate. The authors are inclined toward the regime-dependent model results, which confirm the nonlinearity and time variation in the relation between precious metals returns and inflation. Overall, their results show that silver provides the strongest hedging performance (in five out of the six countries examined) and that the exchange rate only slightly affects the results in a few instances.

Another stream of studies focuses on single countries; for example, Le Long et al. (2013) and Shahbaz et al. (2014) investigate the gold-inflation relation in Vietnam and Pakistan, respectively. Le Long et al. (2013) use quarterly data on the gold price index of Vietnam from 2001 to 2011. They employ a simple time series Fisher regression in which they regress gold returns on ex post inflation in addition to an ex ante regression specification of gold returns on expected and unexpected inflation. To control for the presence of structural breaks in the time series under consideration, the authors create dummy variables that correspond to several institutional changes that took place in the Vietnamese capital market. The results obtained show strong evidence of a perfect inflation hedging capability of gold against inflation in Vietnam.

Using local gold quarterly data over the 1997-2011 period for Pakistan, Shahbaz et al. (2014) investigate the short- and long-run relation between gold and inflation, controlling for structural breaks and economic growth by means of the ARDL approach to cointegration. Their results document the presence of cointegration between gold and consumer prices. The long-run and short-run analyses indicate that gold can be used in Pakistan as a hedge against inflation in both the short and the long run.

\section{Theoretical framework and methodology}

The hedging ability of different asset classes follows from the Fisher hypothesis. Fisher (1930) holds that expected nominal and real interest rates are linked through the expected rate of inflation, which by definition means that the nominal interest rate and inflation should move in tandem. Fama and Schwert (1977) argue that the proposition that expected nominal returns incorporate the market predictions of the expected rate of inflation extends to other asset classes. 
Our econometric analysis begins with unit root tests, followed by cointegration tests. Following Worthington and Pahlavani (2007), we use the Zivot and Andrews (1992) unit root test, which allows for a structural break, in addition to conventional unit root tests. In the spirit of Hoang et al. (2016), we use the NARDL approach of Shin et al. (2014) to analyze the relationship between gold and consumer prices.

\subsection{Unit root tests and structural breaks}

As a precursor to cointegration analysis, the order of integration of the series under study must be determined by the means of the Dickey and Fuller (1981) and Phillips and Perron (1988) unit root tests. However, Kennedy $(2008,325)$ posits that all standard unit root tests face difficulties in distinguishing between $\mathrm{I}(0)$ and $\mathrm{I}(1)$ series in the presence of a structural break. Furthermore, Bekaert and Harvey (2003, p. 45) argue that "a dominating characteristic of the data [in emerging markets] is a potentially gradual, structural break." Following Worthington and Pahlavani (2007), we employ a Zivot and Andrews's (1992) unit root test allowing for a structural break to ameliorate the potential bias in standard unit root tests in series containing a structural change.

\subsection{The nonlinear autoregressive distributed lag (NARDL) model}

The uncertainty about the order of integration of the series under consideration motivates the use of the Pesaran et al. (2001) ARDL approach to cointegration testing. The main advantage of this approach is that it accommodates testing for the presence of cointegration regardless of whether the series under consideration are both I(1) processes. To perform the test, the unrestricted (conditional) error correction form of the underlying ARDL is specified as:

$$
\Delta P_{t}=\mu+\rho_{1} P_{t-1}+\rho_{2} C P I_{t-1}+\sum_{i=0}^{p} \delta_{i} \Delta C P I_{t-\mathrm{i}}+\sum_{i=1}^{q} \phi_{i} \Delta P_{t-i}+\varepsilon_{t}
$$

where $\mu$ is the drift component; $\rho_{1}$ and $\rho_{2}$ are long-run multipliers; $p$ and $q$ are the lag lengths for $\Delta C P I_{t-\mathrm{i}}$ and $\Delta P_{t-i}$, respectively, typically selected by minimizing either the Akaike information criterion (AIC) or the Schwarz information criterion (SIC); and $\varepsilon_{t}$ represents the white noise error. Shin et al. (2014) develop a cointegrating NARDL model that accommodates short-and long-run nonlinearities via positive and negative partial sum decompositions of the independent variable as $\mathrm{CPI}_{t}^{+}=\sum_{j=1}^{t} \Delta C P I_{j}^{+}=\sum_{j=1}^{t} \max \left(\Delta C P I_{j}, 0\right) \& C P I_{t}^{-}=\sum_{j=1}^{t} \Delta C P I_{j}^{-}=$ $\sum_{j=1}^{t} \min \left(\Delta C P I_{j}, 0\right)$, incorporating the resulting decompositions into the ARDL model to produce the following general form of the NARDL:

$$
\begin{aligned}
\Delta P_{t}= & \mu+\rho_{1} P_{t-1}+\rho_{2}^{+} C P I_{t-1}^{+}+\rho_{3}^{-} C P I_{t-1}^{-}+\sum_{i=1}^{p} \phi_{i} \Delta P_{t-i}+\sum_{i=0}^{q}\left(\delta_{i}^{+} \Delta C P I_{t-i}^{+}+\delta_{i}^{-} \Delta C P I_{t-i}^{-}\right) \\
& +\varepsilon_{t}
\end{aligned}
$$

The superscripts $(+)$ and $(-)$ in equation $(10)$ denote the positive and negative partial sum decompositions defined above, the coefficients $\rho_{2}^{+}$and $\rho_{3}^{-}$capture long-run asymmetry, and the coefficients $\delta^{+}$and $\delta^{-}$measure the short-run asymmetry. Naturally, the long-run symmetry null hypothesis $\rho_{2}^{+}=\rho_{3}^{-}$can be tested using the Wald test. By the same token, the short-run symmetry null hypothesis is $\delta_{i}^{+}=\delta_{i}^{-}$for all $i=0,1, \ldots, q$ under the Wald test. 
If the long-run symmetry hypothesis is rejected, we proceed with the NARDL model in equation (2). The bounds test can be carried out in the usual manner by testing the null hypothesis of no cointegration, in this case defined as $H_{0}: \rho_{1}=\rho_{2}^{+}=\rho_{3}^{-}=0$, against the alternative of cointegration $H_{1}: \rho_{1} \neq 0, \quad \rho_{2}^{+} \neq 0, \quad \rho_{3}^{-} \neq 0$. The calculated $F$-statistic is then compared to a pair of critical values (an upper and a lower bound) that are tabulated in Pesaran et al. (2001).

If the calculated $F$-statistic falls below the lower bound, then there is no sufficient evidence to reject the null, while if it exceeds the upper bound, then the null is rejected, and it can be safely concluded that the series are cointegrated. However, if the calculated $F$-statistic falls within the bounds, then the outcome of the inference is inconclusive. Once the presence of cointegration is confirmed, the long-run relation can be obtained from the reduced-form solution of equation (2), when $\Delta P_{t}=\Delta C P I_{t}^{+}=\Delta C P I_{t}^{-}=0$ :

$$
P_{t}=\Theta_{0}+\Theta_{1}^{+} C P I_{t}^{+}+\Theta_{2}^{-} C P I_{t}^{-}+v_{t}
$$

where $\Theta_{0}=-\mu / \rho_{1}, \Theta_{1}^{+}=-\rho_{2}^{+} / \rho_{1}, \Theta_{2}^{-}=-\rho_{3}^{-} / \rho_{1}$ and $v_{t}$ are random errors.

\section{Data}

The data set comprises monthly observations of the UAE's consumer price index and local gold spot prices. The beginning of the sample corresponds to the launch of the DGCX shariacompliant spot gold contract in December 2015. The sample ends in January 2021. The data are obtained from the Bloomberg terminal.

\section{Results}

As a prerequisite for cointegration analysis, a battery of unit root tests is employed to determine the order of integration of the series under examination. The conventional unit root tests that we use include the Dickey and Fuller (1981) (ADF) and Phillips and Perron (1988) (PP) tests in addition to the Zivot and Andrews (1992) (ZA) unit root test with one structural break. The results of these unit root tests are presented in Table 1.

Looking at the third and fourth columns of Table 1, we can see that both the ADF and PP tests are consistent in showing that gold and consumer prices are integrated of the same order of one, i.e. I(1), regardless of the specification of the test equation (including a constant only or a constant plus trend). The results emerging from the ZA unit root test, however, suggest that we can reject the unit root null in favor of the one-break alternative for the consumer price series only when the constant plus trend is used. It is interesting to note that the ZA unit root tests suggest break points around the periods 2019M05 and 2018M05 for gold prices reflecting the upward trend in gold prices fueled by expectation of interest rates cuts by the Federal Reserve, the breakdown in trade negotiations between the US and China and the coronavirus disease 2019 (COVID-19) pandemic, while consumer prices exhibit breaks around the periods 2017M09 and 2017M12 which corresponds to the introduction of value added tax (VAT) in the UAE for the first time on the 1st of January 2018 and the deflationary pressure that remains evident in spite of the introduction of VAT (Ashkar et al., 2019). Indeed, a visual inspection of Figure 1, which presents the time series plots of gold and consumer prices, corroborates these findings.

Having established that none of the series is integrated of order 2, we now proceed to estimating the NARDL model. To determine the appropriate lag length and whether a deterministic linear trend is required, we estimate equation (2) by ordinary least squares (OLS), including a dummy variable to account for the structural break documented by the ZA test [5], with and without a linear time trend, sequentially up to lag 6 and record the results for each lag length in Table 2. 


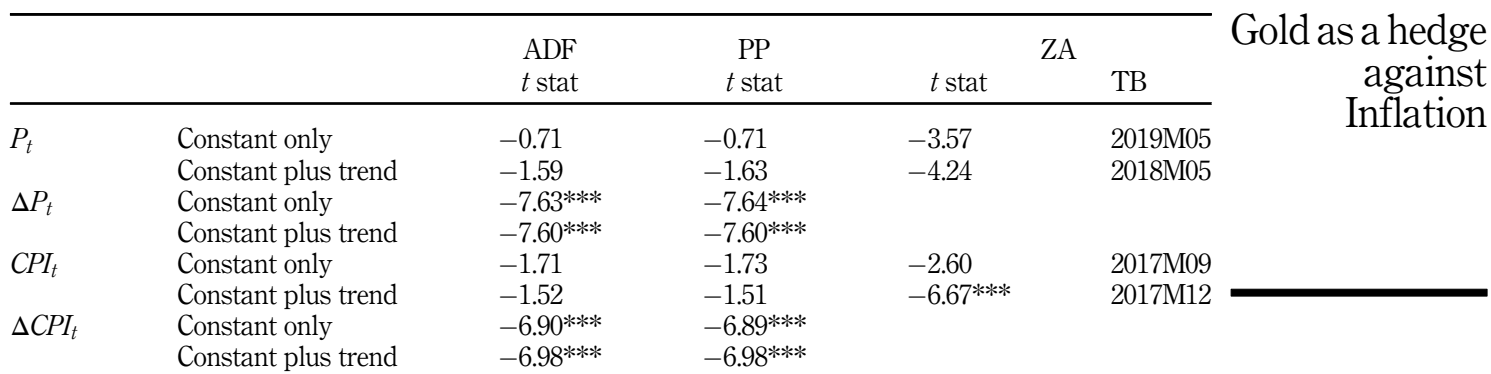

Note(s): ADF = augmented Dickey-Fuller (1981) test; PP = Phillips-Perron (1988) test; ZA = ZivotAndrews (1992) unit root test, allowing for one break; the lag lengths for the ADF and ZA tests are based on the Schwarz information criterion (SIC). *** denotes significance at the $1 \%$ level

Table 1.

Unit root tests

A careful look at Table 2 shows that the lag order selected by the AIC is 5 , irrespective of whether a linear trend is included. As expected, the SIC selects a more parsimonious model than the AIC, choosing 2 lags but favoring the inclusion of a linear trend. Taking into consideration the importance of serially uncorrelated errors for the validity of the bounds tests, we ascertain that there is insufficient evidence to reject the absence of serial correlation across the board. Therefore, we opt for the parsimonious model with more degrees of freedom. The estimation results of the NARDL models are contained in Table 3.

We first direct our attention to model 1 (the full model), which passes all diagnostic tests with no signs of misspecification. Looking at the results pertaining to the Wald tests for shortand long-run symmetry, to arrive at the most suitable specification, we see that the long-run symmetry hypothesis is strongly rejected at the $1 \%$ level, confirming the relevance of the NARDL with long-run asymmetry. The results regarding short-run symmetry are less conclusive in that the short-run symmetry is rejected only for the second lag order. Moving on to the redundant variables test, we can see that terms corresponding to the coefficients $\delta_{0}^{+}, \delta_{1}^{+}$and $\delta_{2}^{+}$can be dropped from the NARDL model, as we have insufficient evidence to reject the hypothesis that they jointly have zero effect. We refer to the reduced model as model 2 , which also passes all diagnostic tests. Only the short-run effects, as represented by the coefficients $\delta_{1}^{-}$and $\delta_{2}^{-}$, which correspond to negative variations in consumer prices at lags 1 and $2\left(\Delta C P I_{t-1}^{-}\right.$and $\left.\Delta C P I_{t-2}^{-}\right)$, are statistically significant. However, they have a positive sign, which means that a fall in consumer prices translates into declines in gold prices, ceteris paribus. This means that gold is not a good hedge against inflation in the short run.

At the bottom of Table 3, we report the results of the bounds test for cointegration based on both models 1 and 2 . We can see that bounds test statistics are highly significant, consistently rejecting the null hypothesis of no cointegration across all cases at the $1 \%$ level. Thus, the long-run relation can be obtained from the reduced-form solution of equation (2) based on the estimates of models 1 and 2, and the estimates of equation (3) are presented in Table 4.

Based on Table 4, we can see that the parameter estimates of the level equations are statistically significant at least at the $10 \%$ level and qualitatively the same across the two model specifications. A word on the interpretation of the level equations may be useful. Consider, for example, the first-level equation for model 2 . For positive variations in consumer prices, a $1 \%$ increase in consumer prices increases gold prices by $1.91 \%$, ceteris paribus. This suggests that gold can be used as a hedge against inflation in the long run. On the other hand, for the negative variations, a $1 \%$ decline in consumer prices increases gold prices by $8.75 \%$, ceteris paribus, implying that investors can also profit from deflation in the long run. 


\section{PRR}

Figure 1.

Monthly variations in gold prices and CPI

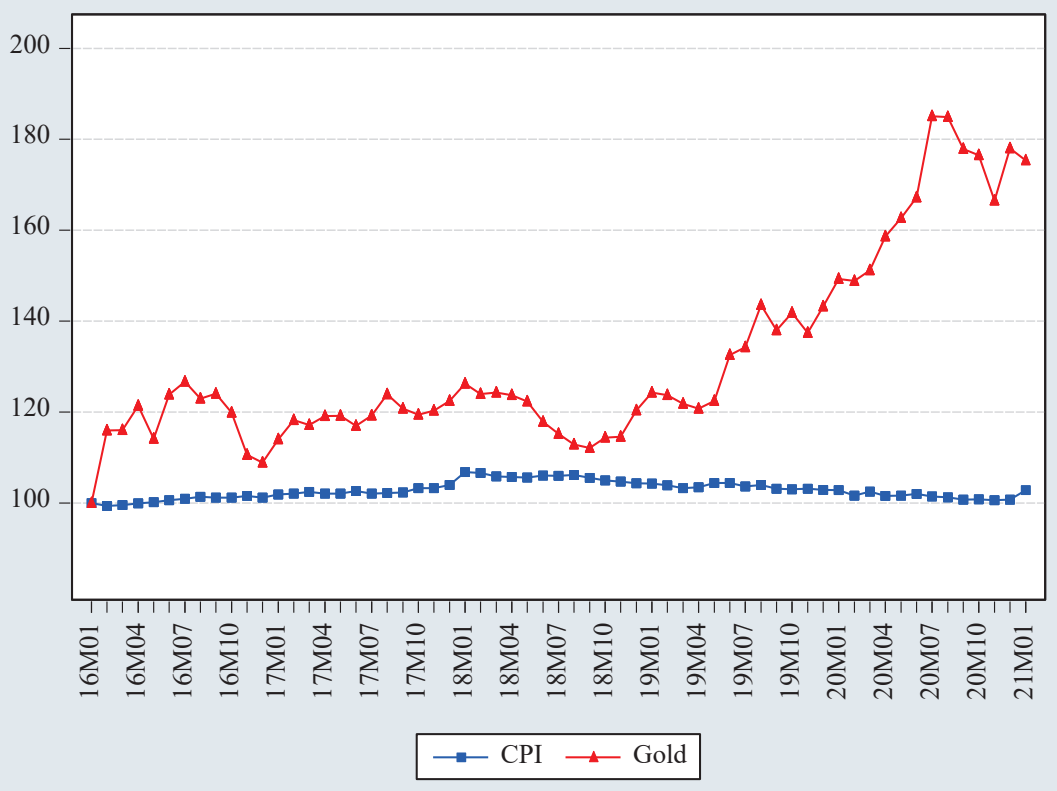

Note(s): To facilitate the comparison between consumer and gold prices, the base of 100 is fixed at the beginning of the sample period

\begin{tabular}{|c|c|c|c|c|c|c|}
\hline$p$ & AIC & $\begin{array}{l}\text { Constant only } \\
\text { SIC }\end{array}$ & B.G (1) & AIC & $\begin{array}{l}\text { tant plus } \\
\text { SIC }\end{array}$ & B.G (1) \\
\hline 1 & -3.84 & -3.49 & 0.75 & -3.84 & -3.45 & 1.21 \\
\hline 2 & -3.96 & -3.50 & 0.07 & -4.05 & $-3.55^{\mathrm{a}}$ & 0.54 \\
\hline 3 & -3.93 & -3.35 & 0.34 & -3.95 & -3.34 & 0.79 \\
\hline 4 & -3.96 & -3.28 & 0.50 & -4.08 & -3.35 & 1.42 \\
\hline 5 & -4.10 & -3.30 & 2.45 & -4.10 & -3.26 & 0.40 \\
\hline 6 & -4.04 & -3.11 & 0.02 & -4.00 & -3.05 & 0.33 \\
\hline
\end{tabular}

Table 2.

Statistics for selecting the lag order
Note(s): $\mathrm{AIC}=$ Akaike information criterion. $\mathrm{SIC}=$ Schwarz information criterion. ${ }^{\text {a Indicates the }}$ corresponding lag order selected by the SIC; B.G (1) = Breusch-Godfrey test for serial correlation based on $\chi^{2}$ statistics

\section{Discussion}

Our findings that gold serves as a good hedge against inflation in the long run only, indeed, are largely at odds with those obtained by Hoang et al. (2016) who arrived at the opposite results. They conclude that while the short-run results are promising as to the hedging effectiveness of gold against inflation in half of the cases (i.e. the UK, the US and India), gold fails to provide a hedge against inflation across all countries in the long run. The seemingly conflicting results between the present study and that of Hoang et al. (2016) can be explained on the following grounds: 


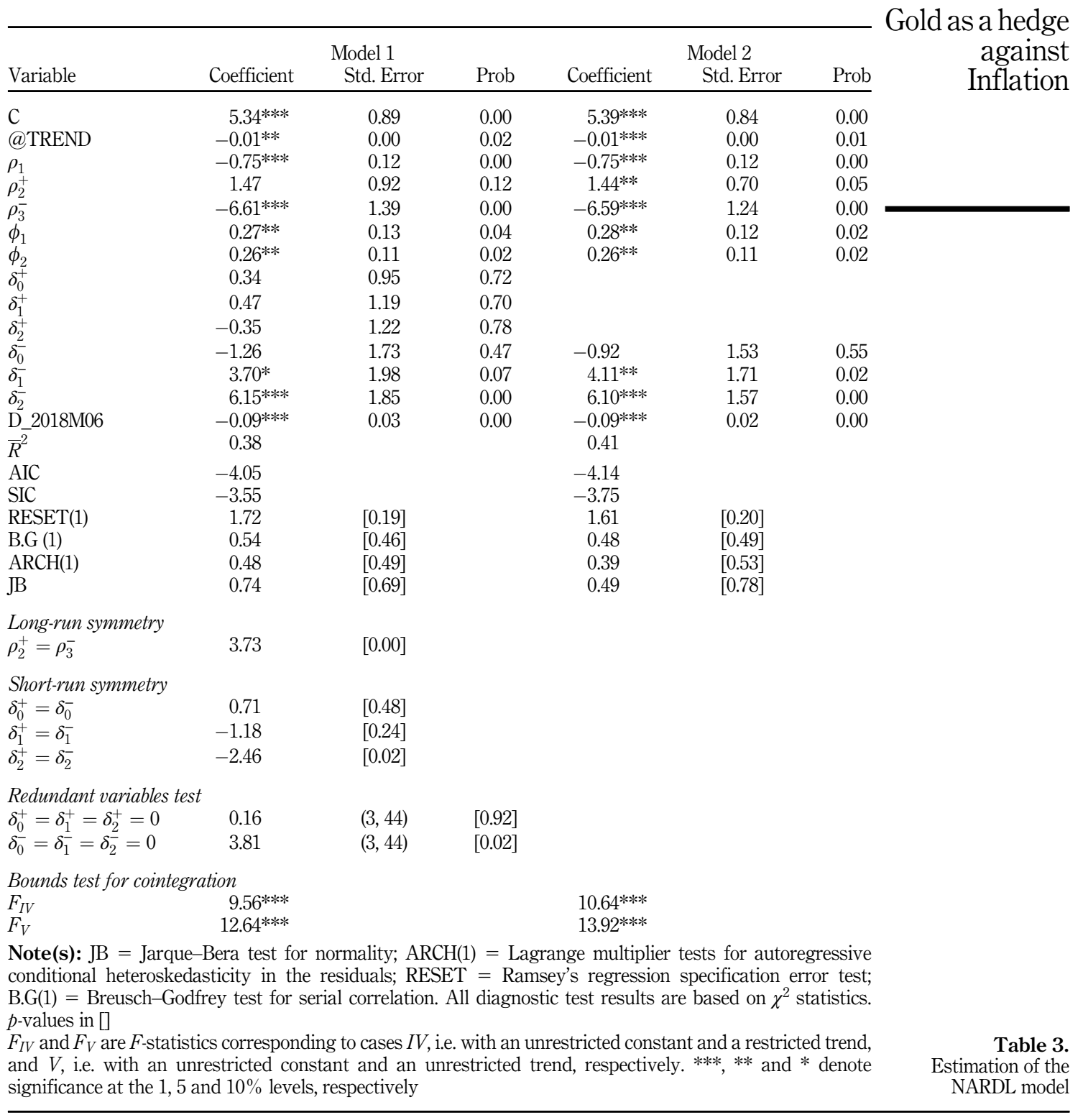

(1) The deflation that occurred in the UAE combined with the persistent upward trend over the past few years in gold prices may have resulted in consumer and gold prices deviating from their long-run equilibrium which is shown to be restored in the long run.

(2) Another possible reason is that Hoang et al. (2016) did not control for structural breaks within their NARDL analysis. 


\section{PRR}

\begin{tabular}{lll} 
& Level equations & \\
Case & Model 1 & Model 2 \\
\hline IV & $P_{t}=1.96 C P I_{t}^{+}-8.84 C P I_{t}^{-}-0.01$ Trend $+v_{t}$ & $\begin{array}{l}P_{t}=1.91 C P I_{t}^{+}-8.75 C P I_{t}^{-}-0.01 T r e n d+v_{t} \\
(2.20)^{* *}(-9.48)^{* * *}(-3.23)^{* * *}\end{array}$ \\
& $\begin{array}{l}(1.75)^{*}(-8.45)^{* * *}(-2.77)^{* * *} \\
P_{t}=1.91 C P I_{t}^{+}-8.75 C P I_{t}^{-}+v_{t} \\
(2.20)^{* *}(-9.48)^{* * *}\end{array}$ &
\end{tabular}

Note(s): ***,** and * denote significance at the 1,5 and $10 \%$ levels, respectively. Case IV is the unrestricted

Table 4.

Long-run analysis constant and restricted trend specification, while case $\mathrm{V}$ is the unrestricted constant and unrestricted trend specification

(3) Disparities in the hedging effectiveness of gold against inflation can result from the changes in the basket of goods and services used to calculate CPI both across countries and over time.

Taken together, the results we obtained (gold being as a good hedge against inflation in the long but not the short run) despite being inconsistent with Hoang et al. (2016), are commonplace in the literature not only for gold and precious metals (for example see, Taylor, 1998; Wang et al., 2011) but also for common stocks (for example see, Al-Nassar and Bhatti, 2019, and the references cited therein). A systematic analysis of external factors that impact the gold price-inflation nexus is required to account for reasons behind the heterogeneity of results across countries, and we aim to explore this issue in our future research agenda [6].

\section{Conclusion}

The frequent occurrence of crises and pandemics in the last few decades brought gold back to center stage as a safe haven in times of heightened uncertainties, which in turn raise an important question as to whether gold can protect the purchasing power of investors against inflation. In this study, we examine this research question in a new context using local gold data from the UAE. To this end, we employ a NARDL model to analyze the relationship between gold and consumer prices. This approach is selected for its multiple merits. The first is that it accommodates testing for the presence of cointegration regardless of whether the series under consideration are both I(1) processes. The second is that it enables us to accommodate nonlinearity and detect the presence of short- and long-run asymmetric relationships between gold prices and inflation simultaneously. The third is that it accommodates the presence of structural breaks.

The results that emerge from our analysis show that gold and consumer prices are cointegrated. Moreover, the long-run asymmetry of the response of gold prices to changes in consumer prices is confirmed. Remarkably, the results suggest not only that gold can serve as a hedge against inflation in the long run but also that declines in consumer prices are associated with increased gold prices, which means that investors can also benefit from holding gold in deflationary times. The results on the short-run relationship between gold and inflation are weak, suggesting that gold is not able to hedge against inflation in the short run. This outcome is mainly driven by the deflation that occurred in the UAE coupled with the upward trend in gold prices in the past few years, resulting in consumer and gold prices deviating from their long-run equilibrium which is shown to be restored in the long run.

The ability of gold to serve as an inflation hedge in the long run justifies the increase in gold reserves on the part of the central bank of the UAE, as they not only can protect the 
purchasing power of the local currency but also can serve as a safe haven in recessionary periods. Additionally, investors can benefit from holding gold in the form of assets or even jewelry.

A caveat of this paper is that we consider a single country. We aim to address this limitation in future work by considering a large sample of countries for which we conduct systematic analysis of external factors that impact the gold price-inflation nexus to explore the reasons behind the heterogeneity of results across countries.

\section{Notes}

1. The price of gold, under this system, was fixed at US\$35 per ounce.

2. Gold-backed ETFs witnessed record inflows of 877 tonnes (US $\$ 47.9 \mathrm{bn}$ ) in 2020, representing assets under management of US $\$ 228.2 \mathrm{bn}$ by the end of the year (World Gold Council, 2021a).

3. Ghosh et al. (2004) classify the demand for gold into two categories: the first is use demand, where gold is utilized to produce jewelry, electrical components, dental restorations, etc., and the second is asset demand, whereby gold is held for investment purposes by governments and investors.

4. The global financial crisis saw gold emerge as a safe haven, a role that it has retained through the current COVID-19 pandemic (see, Akhtaruzzaman et al., 2021; Baur and McDermott, 2010).

5. The stability dummy variable equals 1 over the period 2018:05 up to end of the sample period and 0 otherwise.

6. We thank an anonymous referee for directing our attention to this important point.

\section{References}

Adekoya, O.B., Oliyide, J.A. and Tahir, H. (2021), "What do we know about the inflation-hedging property of precious metals in Africa? The case of leading producers of the commodities", Resources Policy, Vol. 72, 102120, doi: 10.1016/j.resourpol.2021.102120.

Akhtaruzzaman, M., Boubaker, S., Lucey, B.M. and Sensoy, A. (2021), "Is gold a hedge or a safe-haven asset in the COVID-19 crisis?", Economic Modelling, Vol. 102, 105588, 10.1016/j.econmod.2021. 105588.

Al-Nassar, N.S. and Bhatti, R.H. (2019), "Are common stocks a hedge against inflation in emerging markets?", Journal of Economics and Finance, Vol. 43 No. 3, pp. 421-455, doi: 10.1007/s12197018-9447-9.

Arnold, S. and Auer, B.R. (2015), "What do scientists know about inflation hedging?", The North American Journal of Economics and Finance, Vol. 34, pp. 187-214, doi: 10.1016/j.najef.2015. 08.005 .

Ashkar, H., Anderson, S. and Boxshall, R. (2019), "Deflation persists for Gulf economies”, available at: https://www.pwc.com/m1/en/publications/economy-watch/pdf/me-economy-watch-june-2019. pdf (accessed 14 October 2021).

Bampinas, G. and Panagiotidis, T. (2015), "Are gold and silver a hedge against inflation? A two century perspective", International Review of Financial Analysis, Vol. 41, pp. 267-276, doi: 10. 1016/j.j.irfa.2015.02.007.

Batten, J.A., Ciner, C. and Lucey, B.M. (2014), "On the economic determinants of the gold-inflation relation”, Resources Policy, Vol. 41, pp. 101-108, doi: 10.1016/j.resourpol.2014.03.007.

Baur, D.G. and McDermott, T.K. (2010), "Is gold a safe haven? International evidence", Journal of Banking and Finance, Vol. 34 No. 8, pp. 1886-1898, doi: 10.1016/j.jbankfin.2009.12.008.

Beckmann, J. and Czudaj, R. (2013), "Gold as an inflation hedge in a time-varying coefficient framework", The North American Journal of Economics and Finance, Vol. 24, pp. 208-222, doi: 10.1016/j.najef.2012.10.007. 
Bekaert, G. and Harvey, C.R. (2003), "Emerging markets finance", Journal of Empirical Finance, Vol. 10 No. 1, pp. 3-55, doi: 10.1016/\$0927-5398(02)00054-3.

Brown, K.C. and Howe, J.S. (1987), "On the use of gold as a fixed income security", Financial Analysts Journal, Vol. 43 No. 4, pp. 73-76, doi: 10.2469/faj.v43.n4.73.

Chua, J. and Woodward, R.S. (1982), "Gold as an inflation hedge: a comparative study of six major industrial countries", Journal of Business Finance \& Accounting, Vol. 9 No. 2, pp. 191-197, doi: 10.1111/j.1468-5957.1982.tb00985.x.

Dickey, D.A. and Fuller, W.A. (1981), "Likelihood ratio statistics for autoregressive time series with a unit root", Econometrica, Vol. 49 No. 4, pp. 1057-1072, doi: 10.2307/1912517.

Enders, W. and Siklos, P.L. (2001), "Cointegration and threshold adjustment", Journal of Business and Economic Statistics, Vol. 19 No. 2, pp. 166-176, doi: 10.1198/073500101316970395.

Engle, R.F. and Granger, C.W.J. (1987), "Co-integration and error correction: representation, estimation, and testing", Econometrica, Vol. 55 No. 2, pp. 251-276, doi: 10.2307/1913236.

Erb, C., Harvey, C.R. and Viskanta, T. (2020), "Gold, the golden constant, and déjà vu”, Financial Analysts Journal, Vol. 76 No. 4, pp. 134-142, doi: 10.1080/0015198X.2020.1817698.

Fama, E.F. and Schwert, G.W. (1977), “Asset returns and inflation”, Journal of Financial Economics, Vol. 5 No. 2, pp. 115-146, doi: 10.1016/0304-405X(77)90014-9.

Fisher, I. (1930), The Theory of Interest Rates, Macmillan, New York.

Ghosh, D., Levin, E.J., Macmillan, P. and Wright, R.E. (2004), "Gold as an inflation hedge?”, Studies in Economics and Finance, Vol. 22 No. 1, pp. 1-25, doi: 10.1108/eb043380.

Hoang, T.H.V., Lahiani, A. and Heller, D. (2016), "Is gold a hedge against inflation? New evidence from a nonlinear ARDL approach”, Economic Modelling, Vol. 54, pp. 54-66, doi: 10.1016/j.econmod. 2015.12.013.

Jaffe, J.F. (1989), "Gold and gold stocks as investments for institutional portfolios", Financial Analysts Journal, Vol. 45 No. 2, pp. 53-59, doi: 10.2469/faj.v45.n2.53.

Jastram, R.W. (1978), The Golden Constant: the English and American Experience 1560-1976, John Wiley \& Sons, New York.

Johansen, S. (1988), "Statistical analysis of cointegration vectors", Journal of Economic Dynamics and Control, Vol. 12 No. 2, pp. 231-254, doi: 10.1016/0165-1889(88)90041-3.

Johansen, S. (1991), "Estimation and hypothesis testing of cointegration vectors in Gaussian vector autoregressive models", Econometrica, Vol. 59 No. 6, pp. 1551-1580, doi: 10.2307/2938278.

Kennedy, P. (2008), A Guide to Econometrics, Wiley-Blackwell Publishing, Malden, MA.

Kolluri, B.R. (1981), "Gold as a hedge against inflation-an empirical-investigation”, Quarterly Review of Economics and Business, Vol. 21 No. 4, pp. 13-24.

Le Long, H., De Ceuster, M.J.K., Annaert, J. and Amonhaemanon, D. (2013), "Gold as a hedge against inflation: the Vietnamese case”, Procedia Economics and Finance, Vol. 5, pp. 502-511, doi: 10. 1016/S2212-5671(13)00059-2.

Lucey, B.M., Sharma, S.S. and Vigne, S.A. (2017), "Gold and inflation(s) - a time-varying relationship”, Economic Modelling, Vol. 67, pp. 88-101, doi: 10.1016/j.econmod.2016.10.008.

Mahdavi, S. and Zhou, S. (1997), "Gold and commodity prices as leading indicators of inflation: tests of long-run relationship and predictive performance", Journal of Economics and Business, Vol. 49 No. 5, pp. 475-489, doi: 10.1016/S0148-6195(97)00034-9.

Pesaran, M.H., Shin, Y. and Smith, R.J. (2001), "Bounds testing approaches to the analysis of level relationships", Journal of Applied Econometrics, Vol. 16 No. 3, pp. 289-326, doi: 10.1002/ jae.616.

Phillips, P.C.B. and Perron, P. (1988), "Testing for a unit root in time series regression”, Biometrika, Vol. 75 No. 2, pp. 335-346, doi: 10.2307/2336182. 
Refinitiv (2020), "GFMS gold survey 2019 H2 update \& outlook", available at: https://solutions. refinitiv.com/metalsresearch.

Saikkonen, P. and Lütkepohl, H. (2000a), "Testing for the cointegrating rank of a var process with an intercept", Econometric Theory, Vol. 16 No. 3, pp. 373-406, doi: 10.1017/ S0266466600163042.

Saikkonen, P. and Lütkepohl, H. (2000b), "Testing for the cointegrating rank of a VAR process with structural shifts", Journal of Business \& Economic Statistics, Vol. 18 No. 4, pp. 451-464, doi: 10. 1080/07350015.2000.10524884.

Saikkonen, P. and Lütkepohl, H. (2000c), "Trend adjustment prior to testing for the cointegrating rank of a vector autoregressive process", Journal of Time Series Analysis, Vol. 21 No. 4, pp. 435-456, doi: 10.1111/1467-9892.00192.

Salisu, A.A., Ndako, U.B. and Oloko, T.F. (2019), "Assessing the inflation hedging of gold and palladium in OECD countries”, Resources Policy, Vol. 62, pp. 357-377, doi: 10.1016/j.resourpol. 2019.05.001.

Shahbaz, M., Tahir, M.I., Ali, I. and Rehman, I.U. (2014), "Is gold investment a hedge against inflation in Pakistan? A co-integration and causality analysis in the presence of structural breaks", The North American Journal of Economics and Finance, Vol. 28, pp. 190-205, doi: 10.1016/j.najef. 2014.03.012.

Shahzad, S.J.H., Mensi, W., Hammoudeh, S., Sohail, A. and Al-Yahyaee, K.H. (2019), "Does gold act as a hedge against different nuances of inflation? Evidence from Quantile-on-Quantile and causalityin- quantiles approaches”, Resources Policy, Vol. 62, pp. 602-615, doi: 10.1016/j.resourpol.2018. 11.008 .

Sharma, S.S. (2016), "Can consumer price index predict gold price returns?", Economic Modelling, Vol. 55, pp. 269-278, doi: 10.1016/j.econmod.2016.02.014.

Shin, Y., Yu, B. and Greenwood-Nimmo, M. (2014), "Modelling asymmetric cointegration and dynamic multipliers in a nonlinear ARDL framework", in Sickles, R.C. and Horrace, W.C. (Eds), Festschrift in Honor of Peter Schmidt: Econometric Methods and Applications, Springer, New York, NY, pp. 281-314.

Taylor, N.J. (1998), "Precious metals and inflation", Applied Financial Economics, Vol. 8 No. 2, pp. 201-210, doi: 10.1080/096031098333186.

Wang, K.-M., Lee, Y.-M. and Thi, T.-B.N. (2011), "Time and place where gold acts as an inflation hedge: an application of long-run and short-run threshold model", Economic Modelling, Vol. 28 No. 3, pp. 806-819, doi: 10.1016/j.econmod.2010.10.008.

World Gold Council (2021a), "Global gold-backed ETF holdings and flows", available at: https://www. gold.org/goldhub/data/global-gold-backed-etf-holdings-and-flows/2020/december (accessed 25 April 2021).

World Gold Council (2021b), "Monthly central bank statistics", available at: https:/www.gold.org/ goldhub/data/monthly-central-bank-statistics (accessed 10 July 2021).

Worthington, A.C. and Pahlavani, M. (2007), "Gold investment as an inflationary hedge: cointegration evidence with allowance for endogenous structural breaks", Applied Financial Economics Letters, Vol. 3 No. 4, pp. 259-262, doi: 10.1080/17446540601118301.

Zivot, E. and Andrews, D. (1992), "Further evidence on the great crash, the oil-price shock, and the unit-root hypothesis", Journal of Business \& Economic Statistics, Vol. 20 No. 1, pp. 25-44, doi: 10. 1198/073500102753410372.

\footnotetext{
About the author

Nassar S. Al-Nassar is an assistant professor of finance in the Department of Economics and Finance within the College of Business and Economics at Qassim University, Saudi Arabia. After graduating with a degree in economics and business (with 1st class honors) from Qassim University, he completed a master's in finance from the University of Adelaide and a postgraduate diploma in economics and commerce specializing in Finance from Monash University. Dr. Al-Nassar obtained his $\mathrm{PhD}$ in Finance
} 
from RMIT University in 2015. He held several administrative positions within Qassim University, including the Dean of the College of Business and Economics and a member of the University council. His research interests are mainly in the areas of financial market efficiency, funds management, market integration and business education. Nassar S. Al-Nassar is the corresponding author and can be contacted at: nnsaar@qu.edu.sa

For instructions on how to order reprints of this article, please visit our website: www.emeraldgrouppublishing.com/licensing/reprints.htm Or contact us for further details: permissions@emeraldinsight.com 